\title{
POR UMA GRAMÁTICA AMERÍNDIA: EM UM MUNDO ONDE CAIBAM MUITOS MUNDOS
}

\author{
Maurício Beck ${ }^{1}$
}

Resumo: Neste artigo, discorro acerca do discurso do levante zapatista e a relação deste com a estrutura morfossintática da Língua Tojolabal, de família maia. O objetivo é investigar alguns efeitos de sentido, em parte determinados pela materialidade lingüística do Tojolabal, nos comunicados do Exército Zapatista de Libertação Nacional.

Palavras-chave: zapatismo; língua ameríndia; base lingüística.

Inicio por uma espécie de retificação de um equívoco cometido por mim em um artigo publicado ano passado ${ }^{2}$ no qual busquei analisar um dos comunicados zapatistas. Tratava-se do comunicado que celebrava o aniversário da morte de Emiliano Zapata. Em certa altura do texto apresentei um conjunto de seqüências enunciativas e, logo em seguida, empreendi um ensaio de análise e interpretação. A seqüência em questão, a que foi equivocadamente interpretada, é a seguinte:

Votán-Zapata são todos os que marcham com nossa bandeira. Votán-Zapata é aquele que caminha no coração de todos e de cada um dos homens e mulheres verdadeiros. Todos somos uno em Votán-Zapata e ele é uno em todos nós (DI FELICE; MUÑOZ, 1998, p. 101).

$\mathrm{Na}$ ocasião, interpretei o sintagma homens e mulheres verdadeiros ressoando sentidos próprios à memória cristã católica mexicana; e que parecia funcionar em conjunto com caminhar no coração de todos como um modo de interpelação de virtus cristã.

O que esse ensaio de interpretação ignorou é que entre os descendentes dos maias há uma etnia chamada Tojolabal. De

1 Doutorando em Letras/Estudos Lingüísticos UFSM/PPGL/Laboratório Corpus, sob orientação da profa Dr. Amanda Eloina Scherer (DLCLL/PPGL/UFSM).

2 O título do artigo é Pacal Votan e Emiliano Zapata: Sincretismo de Mitologias e Mobilização Política como Efeitos de Sentido dos Comunicados Zapatistas e foi publicado nos Anais do VII Seminário Internacional em Letras: Linguagem Cultura e Identidade. Santa Maria, Unifra, 2007. CD-ROOM. 
acordo com Lenkersdorf (1996), Tojolabal deriva do nome do idioma, chamado tojol 'a $a b$ ' al, e que pode ser traduzido por idioma verdadeiro, língua autêntica. ' $a$ ab' al corresponde à palavra, língua, idioma, e tojol a verdadeiro, autêntico e genuíno. As pessoas chamadas tojol, designados tojol winik são os homens verdadeiros.

Contudo, ainda de acordo com Lenkersdorf (1996), para os tojolabales, eles mesmos, enquanto homens verdadeiros, não se percebem como antitéticos a outras culturas - que seria supostamente composta de homens não verdadeiros. Tojol não é uma condição estática ou uma propriedade inerente a um sujeito, pelo contrário, assinala uma certa retitude que se pode alcançar ou perder em um tempo determinado. Não se nasce tojol, mas se faz tojol. É uma possibilidade, um caminho, não uma posse ou propriedade. Todos podem, se compromissados para tanto, tornarem-se em seu tempo tojol winik.

É curioso, sobretudo para quem trabalha com a Análise de Discurso iniciada pelo coletivo de intelectuais em torno de Michel Pêcheux, na década de 1960, o modo como Lenkersdorf (1996) dá nome à postura dos falantes de tojolabal para com o homem branco. Segundo o lingüista, os tojol desde a perspectiva de sua língua, interpelam os falantes das línguas vernáculas de família indoeuropéia.

Antes de explicar melhor a abordagem lingüística deste autor gostaria de trazer à baila a proposta da Gramática da Multidão de Virno (2008) que discorre acerca das perturbações da experiência das sociedades pós-fordistas. Experiência que leva a se recorrer a uma espécie de fundo comum - lugar comum - da cultura ocidental no trato social, nas decisões práticas da vida que não é de todo estranha às etnias maias que se insurgiram contra o exército mexicano.

Também nesse caso não é possível pensar em uma massa homogênea. Nem mesmo em um povo subordinado a seu EstadoNação respectivo, ao menos desde o fim da chamada civilização maia, antes mesmo da chegada de Colombo ao Novo Mundo. Este, aliás, é um ponto que marca uma diferença. A multiplicidade, a heterogeneidade, no caso dos ameríndios camponeses descendentes dos maias não é um fenômeno recente ou marginal, mas é traço da história de resistência de mais de 500 anos.

Talvez a expressão dessa multiplicidade, a visibilidade que ela ganhou na atualidade seja recente. Algo que remonta a migração de diversas etnias maias dos arredores de Chiapas e da Guatemala 
para a Selva Lacandona (BUENROSTRO Y ARELLANO, 2002). Migração decorrente de políticas modernizadoras do governo mexicano. E que, ao reunir novamente as várias línguas de família maia em um mesmo território, forjou as condições de produção do enunciado difundido pelos Zapatistas: Um mundo onde caibam muitos mundos!

Mundo esse que começou a ser construído muito antes do levante zapatista em 1994. Duas décadas antes, em importante congresso indígena, já se deliberava por meio de consenso acerca da união dos múltiplos para tratar dos problemas que os índios enfrentavam: a miséria, a pressão pela modernização e pela propriedade privada das terras em oposição aos costumes locais e as propriedades comunais chamadas ejidades. Já naquela época, de acordo com Buenrostro y Arellano (Ibid.), os ameríndios tinham claro quais eram seus problemas.

Voltando à obra de Lenkersdorf (1996) e sua afirmação de que os falantes tojol, desde a cosmovisão deles, interpelam a nós, sujeitos falantes de línguas vernáculas - de cosmovisão ocidental. A proposição de Lenkersdorf (Ibid.) é de que a sintaxe da Língua Maia afeta sua cosmovisão e mesmo a relação que os falantes estabelecem entre si e com outras culturas. Para corroborar com essa afirmação, o autor apresenta alguns exemplos do modo como enunciados maias se estruturam e como diferem quando são 'traduzidos' para a sintaxe do Espanhol.

Ademais, para Lenkersdorf (1996), na Língua Tojolabal, não há a clássica subordinação ou hierarquia sintática: sujeito-objeto. Em tojolabal, só há sujeitos. Sujeitos agenciais e sujeitos vivenciais. A Língua Tojolabal seria, por conseguinte, uma língua intersubjetiva. E diferiria das línguas indo-européias por não se estruturar conforme o modelo sujeito + verbo + complemento. Não há um sujeito centralizador do discurso, mas sujeitos que, de modo coordenado, possibilitam que um acontecimento vivencial ou agencial se efetue. Ao invés de uma sintaxe piramidal, o que temos na estrutura Tojolabal é uma sintaxe horizontal.

Antes de apresentar alguns exemplos concretos da sintaxe maia para embasar estas asserções teóricas, gostaria de falar de um outro sentido para essa interpelação maia-tojolabal. Trata-se da interpelação do levante zapatista propriamente dito, que através de comunicados, incita os mexicanos, povos e governos do mundo a ouvir o que os camponeses indígenas têm a dizer. Na cosmovisão tojolabal, ouvir significa respeitar o outro, reconhecer a dignidade do 
outro. Sem esses atributos não há possibilidade de comunicação para os falantes das etnias maias.

É interessante notar, desde a perspectiva da $A D$, que essa interpelação se deu por meio de um acontecimento histórico preciso: O levante zapatista em janeiro de 1994. Este se dá pelo diálogo entre culturas muito diferentes que partilham um mesmo territórionação. Ademais, é a materialidade da língua (sua equivocidade, sua não transparência) um fator importante na disputa ideológica, disputa entre direcionamentos de sentidos diversos.

Passemos aos exemplos trabalhados por Lenkersdorf (1996, p. 28) para embasar essas conjeturas.

\section{Exemplo 1:}

\section{Les dije - kala awab'yex.}

A frase em Castelhano é composta dos seguintes elementos sintáticos: les - pronome pessoal (terceira pessoa do plural), funcionando como objeto indireto; $\mathbf{d i j}(\mathrm{e})$ - verbo transitivo, decir, voz ativa, indicativo, pretérito; e - sufixo agregado ao verbo que assinala o sujeito implícito da primeira pessoa do singular eu.

Vejamos em Tojolabal: k- prefixo agencial da primeira pessoa do singular; -ala verbo agencial vocálico (decir), aspecto completivo; aw- prefixo agencial da segunda pessoa, completado pelo sufixo yex que assinala o plural da mesma pessoa (vocês). Este prefixo representa o segundo sujeito; ab'- raiz do verbo 'ab'i (escuchar, oír, etc.). A forma não permite interpretar de maneira inequívoca 0 aspecto-tempo em questão. Pode ser completivo, incompletivo ou futuro. Deduz-se que segue o verbo kala, e é completivo.

$\mathrm{O}$ que primeiro se deduz desse cotejo entre o Tojolabal e o Castelhano efetuado por Lenkersdorf (1996), pois enquanto no enunciado em Espanhol há apenas um sujeito cuja ação expressa o verbo - ao qual se agrega um objeto indireto -, no enunciado em Tojolabal se apresentam dois sujeitos agenciais (yo e ustedes). Sendo que cada sujeito exerce a ação que lhe corresponde. O primeiro dije, o segundo escucharan.

Observemos que o objeto indireto do espanhol se transformou em outro verbo agencial com o sujeito agencial correspondente. Uma tradução mais próxima, alheia à estrutura do espanhol seria portanto: (Lo) dije. Ustedes (lo) escucharan. (Ibid., p.30) 
De acordo com Lenkersdorf (Ibid.) a razão para que essa frase-exemplo se estruture desse modo é que para os tojol o fato comunicativo só pode ocorrer com a cooperação de dois sujeitos. Se trata de um intercambio entre iguais. A comunicação é entendida como um processo bidirecional.

Exemplo 2: (LENKERSDORF, 1996, p. 42)

\section{Stelawon - Me abrazó.}

Em Tojolabal: s - prefixo agencial, terceira pessoa (ele ou ela), sujeito agencial. -tela- verbo agencial, aspecto completivo (abraçar) -w- consoante de enlace. -on - sufixo vivencial, primeira pessoa (eu), sujeito vivencial.

Em Espanhol: me pronome pessoal, primeira pessoa do singular, objeto direto. Abrazó- verbo transitivo, pretérito, sujeito implícito no sufixo. -ó que representa a terceira pessoa do singular. Tradução mais aproximada (lbid., p. 44): Tengo la vivencia - su abrazar.

Esse exemplo embasa a afirmação de Lenkersdorf (1996) de que em Tojolabal o objeto ascende a sujeito. Ou seja, no idioma maia-tojolabal não existem objetos diretos, em seu lugar encontramos sujeitos vivenciais. Lembrando que para o autor sujeitos vivenciais se constituem em uma classe muito mais ampla que a de sujeito paciente da voz passiva nas línguas indo-européias.

$\mathrm{O}$ autor infere que a presença de sujeitos vivenciais exclui a de objetos diretos. Logo, em Tojolabal, não há objetos diretos ou indiretos. Visto que, para Lenkersdorf (1996), complementos que dão determinação de tempo, lugar, modo independem dos sujeitos da frase e, por conseguinte, distinguem-se sintática e semanticamente dos objetos diretos e indiretos.

Outrossim, em Tojolabal os verbos são divididos em agenciais - referentes aos sujeitos agencias que co-participam de um acontecimento -, e em vivenciais - que expressam experiências pela respectiva classe de sujeitos.

Ao que tudo indica a perspectiva da materialidade lingüística do Tojolabal afeta não somente o modo como os falantes da língua interpretam o mundo e suas relações, mas também a forma como estes mesmos sujeitos interpelam os falantes de línguas não maias. A interpelação do homem branco, que com eles divide ou disputa o mesmo território, é determinada pelas condições de produção 
ideológicas de dadas formações sociais, sendo que a base material das línguas maias parece ser um importante fator entre essas condições.

\section{Referências Bibliográficas}

BUENROSTRO Y ARELLANO, A. As Raízes do Fenômeno Chiapas: 0 Já Basta da Resistência Zapatista. Trad. de Maria Encarnacion Moya. São Paulo: Alfarrabio, 2002.

DI FELICE, M.; MUÑOZ, C. A Revolução Invencível. Subcomandante Marcos e Exército Zapatista de Libertação Nacional. Cartas e Comunicados. Boi Tempo: São Paulo, 1998.

LENKERSDORF, C. Los Hombres Verdaderos: Voces y Testimonios Tojolabales. Cerro Del Agua, Coyocán, México: Siglo Veintiuno, 1996.

VIRNO, P. Gramática da Multidão. Para uma Análise das Formas de Vida Contemporâneas. Tradução de Leonardo Retamoso Palma. Disponível em: http://br.geocities.com/autoconvocad/gramatica da multidao.html. Acesso em 29 de out. 2008. 